\title{
EDUCAÇÃO AMBIENTAL COMUNITÁRIA E A CONSERVAÇÃO DO LITORAL BRASILEIRO: A EXPERIÊNCIA DO LABORATÓRIO DE EDUCAÇÃO AMBIENTAL EM ÁREAS COSTEIRAS - CENTRO DE CIÊNCIAS TECNOLÓGICAS DA TERRA E DO MAR - CTTMAR/UNIVALI
}

\author{
MATAREZI, J. ${ }^{1}$ \& L.E.C. BONILHA ${ }^{2}$ \\ ${ }^{1}$ CTTMar/UNIVALI - Lab. de Educação Ambiental em Áreas Costeiras. \\ ${ }^{2}$ CTTMar/CEJURPS/ UNIVALI - Lab. de Educação Ambiental em Áreas Costeiras.
}

\section{RESUMO}

\begin{abstract}
As praias e os demais ecossistemas litorâneos, sempre foram locais de recreação e elevado valor estético, destacando-se como o primeiro ambiente a atrair a atenção dos Educadores Ambientais pioneiros do Brasil. A forte relação entre pesquisador e objeto de estudo, sempre aproximou pesquisadores da área ambiental marinha, como oceanógrafos e biólogos, para atividades educativas, voltadas à conservação ambiental. Estas atividades a partir da década de 1980 consolidaram-se ao longo de todo o litoral brasileiro na forma de importantes projetos, muitos deles com grande engajamento comunitário e expressão nacional. Estes exemplos ilustram a grande vinculação histórica até hoje existente entre a Educação Ambiental e profissionais da área de meio ambiente.Apesar do avanço da legislação, a Educação Ambiental vem sendo inserida no ensino superior brasileiro com atraso histórico. A inserção no ensino fundamental e médio, via de regra constitui-se de iniciativas esparsas, sem amparo de programas formais, carecendo de embasamento teórico e metodológico. Dentro deste cenário destaca-se a importância da responsabilidade social da Universidade, tanto no desenvolvimento de saber acadêmico, quanto no suporte técnico para inserção da E.A. no ensino fundamental e médio. Esta responsabilidade contrasta com a grande carência de cursos de pós-graduação em E.A. no Brasil, e uma necessidade de consolidar E.A. como campo do saber e objeto de pesquisa e ensino na academia. Dentro desta perspectiva o Laboratório de Educação Ambiental - LEA - da UNIVALI, locado no Centro de Ciências Tecnológicas da Terra e do Mar (CTTMar), vem contribuindo para a inserção curricular da E.A. no ensino superior. Atualmente vem trabalhando dentro dos cursos de formação na área ambiental, produzindo e disseminando experimentos e práticas pedagógicas em Educação Ambiental na Zona Costeira, e executando projetos em parceria com movimentos de base comunitária, ONG's Ambientalistas, e Prefeituras Municipais na porção centro-norte do litoral catarinense.
\end{abstract}

Palavras Chave: Educação Ambiental Comunitária, Unidades de Conservação, Zona Costeira, Oceanografia, Universidade e Responsabilidade Social.

\section{COMMUNITARY ENVIRONMENTAL EDUCATION AND BRAZILIAN \\ COASTLINE CONSERVATION: THE EXPERIENCE OF COASTAL ENVIRONMENTAL EDUCATION LABORATORY - CENTER OF TECHNOLOGICAL SCIENCE OF EARTH AND SEA - CTTMAR/UNIVALI}

\footnotetext{
ABSTRACT

Beaches and other coastal ecosystems were always considered recreational places with high aesthetic value. In Brazil these ecosystems were the first places that had attracted the
} 
formers Environmental Educators' attention. The huge relation between researchers and study subjects, approached marine environmental researchers as oceanographers and biologists for educational activities, aimed to environmental conservation. These activities since 1980's had consolidated important projects along all Brazilian coastline, so that, most of them with great community involvement, attaining national expression. These examples state the great historical binding among Environmental Education (E.E.) and environmental workers, which stills exists until now. Despite the law advances, the Environmental Education is being introduced at the Brazilian college, with a historical delay. The insertion in to basic and highschool educational system generally makes part of widespread initiatives, without support of formal projects and also theoretical and methodological background. Within this scenario highlights the importance of social function of University as into the academic knowledge development, as than into technical support for insertion of E.E. into the highschool and basic levels. This responsibility withstands with the great lack of graduating courses in E.E. in Brazil and a needing of carrying out E.E. into the academic place such as knowledge field, researching subject and teaching. In this point of view, the Environmental Education Laboratory - Laboratório de Educação Ambiental / LEA - of UNIVALI, located at the Center of Technological Science of Earth and Sea (CTTMar), is helping out the insertion of E.E. into the University curriculum. At the present it's working out within courses at the environmental sciences area, producing and spreading out experiments and pedagogic practices in E.E. at the coastal zone and performing of partnerships with community based social movements, and social groups, such as Environmental NGO's, and also city halls in to the center-north area of Santa Catarina state coastal zone.

Keywords: Environmental Education, Community, Protected Areas, Coastal Zone, Oceanography, University and Social Responsibility

\section{INTRODUÇÃO}

Profundas mudanças se anunciam na educação como a concebemos hoje. Certamente serão mudanças estruturais e funcionais que marcarão um novo caminho a ser percorrido por todos nós Educadores. "Aprender a conhecer", "aprender a fazer", "aprender a viver junto" e "aprender a ser" são os quatro pilares deste novo tipo de Educação, segundo o Relatório DELORS (1999) elaborado pela Comissão Internacional Sobre a Educação para o Século XXI, ligada à UNESCO.

Estas mudanças acompanham os alertas trazidos pelas crises ambientais, sociais, econômicas e de valores humanos, decorrentes dos modelos de desenvolvimento originados pelas Revoluções Industrial e Tecnológica, e centrados na modernidade, no reducionismo, na visão mecanicista de mundo e numa suposta crença de que sempre serão encontradas soluções técnicas para os graves problemas que se apresentam para a humanidade (Mito da Tecnologia).

Para Basarab Nicolescu (1999): "O pensamento mecanicista do século XVIII e sobretudo do século XIX (que predomina ain- da hoje) concebe a Natureza não como um organismo, mas como uma máquina, que basta ser desmontada peça por peça para ser totalmente possuída. O postulado fundamental do pensamento mecanicista é que a natureza pode ser conhecida e conquistada pela metodologia científica, definida de maneira completamente independente do homem e separada dele. A visão triunfalista da "conquista da Natureza" esta enraizada na tremenda eficácia tecnológica desse postulado".

Uma das conseqüências desta conquista científica e tecnológica foi que a sociedade atual acumulou uma perda de contato com a sua base biológica e ecológica, maior do que qualquer outra cultura e civilização no passado (Bissio, 1991). Isto é agravado pelo fato do nosso desligamento da natureza começar desde cedo, quando a maioria das crianças é obrigada a uma vivência eminentemente urbana. Basta mencionar que atualmente a maior parte da população mundial (60\%), e conseqüentemente das crianças, vive nas grandes cidades e metrópoles, dentro de um meio artificializado, privando-se de um contato direto e permanente com a natureza. Este fato gera graves 
distorções na compreensão humana da natureza, influenciando fortemente a percepção ambiental, por conseqüência, o grau de consciência sobre a conservação da Biodiversidade, com implicações para as diversas dimensões da sustentabilidade planetária (cultural, ambiental, social, econômica, tecnológica, institucional e política). Essa separação também se manifesta numa flagrante disparidade entre o desenvolvimento do poder intelectual, o conhecimento científico e a qualidade tecnológica, por um lado, e a sabedoria, espiritualidade e a ética, por outro (Rebouças, 1989).

Tais questões refletem posturas assumidas pela humanidade que parecem ignorar ou simplesmente menosprezar a conexão e as relações elementares que existem entre a vida e o meio ambiente, evidenciando uma crise ambiental sem precedentes na história da humanidade. Torna-se imperativo e um constante desafio ao conhecimento científico, entender essas relações dinâmicas nos mais variados contextos, o que tem levado a humanidade a sucessivas rupturas epistemológicas e a ao confronto com um novo "paradigma", que é o de mudar a concepção mecanicista do mundo (que reduziu o real a um único nível e o homem a apenas sua dimensão física, enquanto sujeito ou objeto), para uma visão holísta da realidade, na perspectiva de uma Cultura Transdisciplinar que integre os diferentes níveis de realidade e amplie nossa consciência social, ecológica, planetária e espiritual.

Segundo Ab'Saber (1991), "garantir a existência de um ambiente sadio para toda a humanidade implica em uma conscientização realmente abrangente, que só pode ter ressonância e maturidade através da Educação Ambiental (E.A.). Um processo educativo que envolva ciência e ética e uma nova filosofia de vida".

\section{A TRAGETÓRIA DA EDUCAÇÃO AMBIENTAL}

Apesar da ciência contemporânea evidenciar os limites da concepção mecanicista do universo, apontando para novos paradigmas emergentes, o Sistema Educacional, ainda possui forte condicionamento mecanicista, disciplinar, individualista e tecnicista. Isto nos faz perguntar que conhecimentos, conceitos, valores e atitudes são necessários para a transformação do mundo e da realidade educacional? E qual a responsabilidade social das Universidades neste processo?

Desde as décadas de 60 e 70, a humanidade, representada pela Organização das $\mathrm{Na}$ ções Unidas (ONU), vem debatendo e propondo alternativas para o atual modelo de desenvolvimento na tentativa de uma maior sustentabilidade da vida no planeta e das sociedades. Todas as conferências mundiais que versaram sobre a "questão ambiental", enfatizaram a importância de se contemplar a questão educativa neste novo projeto de civilização. Assim, surge a Educação Ambiental, iniciando um novo caminho no campo da Educação e das transformações sociais, ambientais e dos valores humanos.

O surgimento e maturação do conceito de Educação Ambiental foi construído a partir de uma série de Conferência Internacionais entre as décadas de 1970 e 1990: Conferência das Nações Unidas sobre Meio Ambiente Humano (Estocolmo, 1972), Seminário realizado em Jammi (1974), Seminário Internacional de Educação Ambiental (Belgrado, 1975), Conferência Internacional sobre E.A. de Tbilisi (URSS, 1977), Congresso Internacional sobre Educação e Formação relativas ao Meio Ambiente (Moscou - URSS, 1987), Conferência das Nações Unidas para o Meio Ambiente e Desenvolvimento (CNUMAD) - Rio'92, e a Conferência Internacional de Meio Ambiente e Sociedade: Educação e Sensibilização do Público para a Viabilidade - 20 anos de Tbilisi, realizada em Thessalonique (Grécia, 1977). A partir destes eventos muito se têm discutido sobre os papéis da E.A. frente aos desafios do presente.

Foram recomendações originadas nestes eventos que justificaram o surgimento de inúmeros projetos e programas de E.A. nas 
mais variadas regiões e realidades, todos convergindo em características, princípios e objetivos; sendo que somente a partir da Conferência de Estocolmo (1972) é que a Educação Ambiental passou a ser estratégica e fundamental para as ações de transformação da sociedade e do meio ambiente, adquirindo a devida importância internacional. Tanto que, em resposta à Recomendação 96 da Conferência de Estocolmo, a Organização para Educação, a Ciência e a Cultura das Nações Unidas (UNESCO) e o Programa das Nações Unidas para o Meio Ambiente (PNUMA), criaram em 1975, o Programa Internacional de Educação Ambiental (PIEA) com o propósito de disseminar, consolidar e promover a EA em seus países membros.

Para Medina (1994), o conceito de Educação Ambiental tem evoluído de forma vinculada ao de meio ambiente e como este vem sendo interpretado. Assim, Educação Ambiental e Meio Ambiente, por serem conceitos dinâmicos e complexos, possibilitam interpretações variadas em função dos referenciais teóricos adotados, o que têm gerado representações sociais diversas, conforme evidenciado por Reigota (1994, 1995 e 1999). Este autor considera que as representações sociais de Meio Ambiente são determinantes e condicionam as concepções de Educação Ambiental e conseqüentes práticas pedagógicas.

"Educação Ambiental" passa a ser um conceito dinâmico e em constante evolução, assim como o conceito de "Meio Ambiente", gerando várias concepções e práticas educacionais como evidenciado por Sato (no prelo) e Sauve (1999, apud Edamaz, 2000).

O conceito de Educação Ambiental mudou desde as décadas de 60 e 70, quando se assemelhava em muito com atividades de ecologia, biologia e preservação da natureza, estimulando, num primeiro momento, um retorno à chamada primeira natureza (natureza intocada) e uma visão romântica de mundo. Simultaneamente, o forte debate da questão ambiental foi marcado pela concepção alarmista e catastrófica dos problemas ambientais, apontados pelas Organizações não Governamentais (ONG's), pelo Movimento Ambientalista e por grupos de cientistas. Esta vertente da Educação Ambiental denominada de ecológicopreservacionista por Medina (op. cit.), influencia a prática de muitos educadores ambientais ainda hoje.

Outra concepção de EA enfoca o diagnóstico e a resolução de problemas concretos, que na maioria das vezes fica na mera constatação de fatos e danos ambientais. $\mathrm{Ou}$ seja, fica restrita a ações isoladas e executadas em datas comemorativas e eventos específicos relativos ao meio ambiente. Muitas vezes é caracterizada por um tom alarmista e catastrófico da questão ambiental apenas identificando os problemas ambientais e deixando transparecer uma grande dificuldade na resolução destes. A vantagem é que aqui já surgem interfaces entre as questões sociais e ambientais, a partir de um problema concreto. Contempla-se neste conjunto vários princípios e objetivos preconizados pelos primeiros encontros e conferências internacionais.

Finalmente podemos destacar um grupo de concepções de EA que considera os problemas ambientais como conseqüência de processos de transformação e construção histórica, cultural e tecnológica, cujas ações, são em sua maioria, localizadas no tempo e no espaço. Este grupo se enquadra na vertente sócioambiental da EA, proposta por Medina (op cit). É neste sentido que se procura colocar em práticas os objetivos e princípios da EA bem como do conceito de EA definido pela UNESCO (1980):

"A Educação Ambiental é o processo de reconhecimento de valores e elucidação de conceitos que levam a desenvolver as habilidades e as atitudes necessárias para entender e apreciar as inter-relações entre os seres humanos, suas culturas e seus meios físicos. A Educação Ambiental também envolve a prática para as tomadas de decisões e para as auto-formulações de comportamentos sobre os temas re- 
lacionados com a qualidade do meio ambiente."

Reigota (1994) reconhece este processo de educação ambiental como uma educação política, na medida em que prepara os cidadãos para exigirem justiça social, cidadania nacional e planetária, autogestão e ética nas suas relações com a sociedade e com a natureza. Tal concepção coloca a EA como fundamental na construção de um novo tipo de sociedade sustentável, onde se busca a construção da cidadania mediante projetos de transformações sociais e ambientais espelhadas nas diversas culturas e suas respectivas identidades.

No Brasil, a Educação Ambiental passa a constar na Constituição Federal de 1988, como incumbência do poder público, juntamente com a promoção da conscientização social para a defesa do meio ambiente. Apesar dos evidentes problemas estruturais e carência da educação formal no País, os Estados e Municípios têm criado instrumentos legais que determinam a EA em quase todos os níveis e esferas da sociedade.

Ressalta-se que a Educação Ambiental esteve associada inicialmente aos órgãos e instituições governamentais e não governamentais ligados ao "meio ambiente"; e não aos da Educação propriamente dito. Isto só veio ocorrer mais tarde, notadamente agora com a incorporação dos Novos Parâmetros Curriculares Nacionais (PCN's) e a definição do Programa Nacional de Educação Ambiental (MEC, 1997). Estes eventos associados aos compromissos assumidos pelo Governo brasileiro no âmbito internacional levaram a elaboração da Política Nacional de EA, sancionada em abril de 1999, na forma de Lei Federal e que ainda está em fase de implantação, desencadeando os processos de elaboração dos programas e políticas estaduais de E.A. Mas, e em nossas Universidades? Como se tem efetivado esta nova proposta de ensino/aprendizagem?

\section{EDUCAÇÃO AMBIENTAL E O PAPEL DAS UNIVERSIDADES}

Como que um reflexo tardio desse processo, a Educação Ambiental também chega ao sistema educacional superior somente agora, neste final de milênio, acumulando um atraso de quase 30 anos. Apesar de poucos exemplos isolados, de forma quase generalizada, nossas Universidades estão apenas começando a perceber suas responsabilidades neste processo, e a despertar para a importância da Educação Ambiental como catalisadora de transformações sócio-ambientais.

As primeiras experiências de Educação Ambiental, nas universidades do Brasil, se deram do Ensino Superior para o ensino fundamental, sempre com predominância dos aspectos ecológicos. Grande parte dessas experiências e iniciativas estavam vinculadas a professores de Universidades e/ou Institutos de pesquisa e educação e em alguns casos aos chamados colégios de aplicação.

Como referência histórica, Silvia Czapski (1998) cita o:

"trabalho do professor Carlos Nobre Rosa, da pequena cidade de Jaboticabal (SP), que na década de 50 decidiu levar seus alunos para fora da sala de aula, para a observação de ambientes e coleta de materiais. A proposta teve grande repercussão entre professores de outras regiões quando o professor Nobre escreveu o livro "Animais em Nossas Praias", com a descrição de sua experiência". Czapski relata ainda que, em 1965, "o professor José Maria de Almeida Júnior introduziu o ensino de ecologia para o colegial do Colégio de Aplicação da Faculdade de Filosofia, Ciências e Letras da USP, em São Paulo (SP). Nesta disciplina ele coordenou a Operação Litoral I, que levou os alunos a praia de São Sebastião, no litoral paulista. Esta foi uma experiência inovadora em que os alunos tiveram uma participação ativa em todas as etapas, desde a preparação, execução, avaliação e apresentação dos resultados na feira de ciências organizada pela 
escola".

Assim, a Praia e o litoral brasileiro surge como um dos vários temas relevantes nas primeiras ações de E.A. no Brasil.

De acordo com o Relatório do Brasil para a CNUMAD (BRASIL, 1991), os primeiros projetos de $\mathrm{E}$. A. em escolas (públicas ou privadas) brasileiras, começaram a surgir em 1975, iniciando um processo que se acelerou e atingiu maior dimensão na década de 80 . Foi neste período que a problemática ambiental transformou-se em questão política relevante, as liberdades democráticas abriram espaço para as comunidades expressarem suas reivindicações e houve a proliferação das organizações conservacionistas. Vale lembrar que o maior mérito da Educação e Conscientização Ambiental no país, até então, coube aos movimentos da própria sociedade civil, como ONG's, veículos de comunicação e dos movimentos políticos, sociais e culturais em defesa do meio ambiente.

Atualmente, poucas Instituições de Ensino Superior têm criado programas de Educação Ambiental, em alguns casos, vinculados a Laboratórios e Núcleos de E.A. Embora a prática da E.A. esteja também associada à Extensão Universitária e às instituições e organizações ligadas ao meio ambiente, são as Universidades que parecem estar produzindo algum saber na área, conforme Pedrini (1997), no entanto, ressalta-se a grande carência de Programas de Pós Graduação em Educação Ambiental no Brasil, e paradoxalmente é na própria academia onde se encontra a grande resistência a práticas educacionais inovadoras.

Visando especificamente a inserção e disseminação da E.A. nas Universidades, a Coordenadoria de E.A. do Ministério de Educação (MEC), realizou uma série de cursos de capacitação para as Universidades, de forma regionalizada mediante metodologia específica (Medina, 2000). A capacitação para as Universidades da Região Sul (Paraná, Santa Catarina e Rio Grande do Sul) ocorreu em Florianópolis (SC) no período de 04 a 08 de maio de 1988, configurando-se num momento importante para os Educadores Ambientais que atuam nas universidades, na definição de formas de integração intra e interinstitucional e de estratégias comuns para a inserção da E.A. no ambiente universitário. Um dos pontos discutidos foi a forma de inserção da E.A. nas Universidades, se de forma disciplinar ou não.

A Lei Federal №. 9.795, que dispõe sobre a Política Nacional de Educação Ambiental diz que a E.A. será desenvolvida como uma prática educativa integrada, contínua e permanente em todos os níveis e modalidades do ensino formal e que não deve ser implantada como disciplina no currículo de ensino (Art. 10 $\S 1^{\circ}$.). Mas, como a E.A. já adquiriu contornos e amplitude como "campo de saber" específico, implicando inclusive em uma profissionalização com relação ao mercado de trabalho, há que se discutir sua inserção como disciplina no Ensino Superior, uma vez que atualmente esta é a forma como se está viabilizando a sua inserção no sistema universitário brasileiro isto é, via de regra, através de uma disciplina. A própria Lei №. 9.795, faculta a criação de uma disciplina específica nos cursos de pós-graduação, extensão e nas áreas voltadas aos aspectos metodológicas da Educação Ambiental, quando se fizer necessário (Art. $10 \S 2^{\circ}$.). Por outro lado, todas as conferências internacionais reafirmam a urgência em capacitar e formar Educadores Ambientais nas mais diversas áreas de atuação profissional. Assim, a E.A. surge como campo propício à integração Universidade/Comunidade, mediante Ensino, Pesquisa e Extensão, por ser de natureza eminentemente interdisciplinar, assim como a "questão ambiental".

Como conseqüência direta deste momento, vários grupos se mobilizaram e organizaram alguns eventos acadêmicos de Educação Ambiental em seus estados, sendo possível o intercâmbio de diversas experiências entre as Instituições. Como referência podemos citar as Universidades do estado do Paraná, que instituíram o Encontro Paranaense de Educação Ambiental, sendo o primeiro realizado 
em 1998, na cidade de Curitiba (PR) pela Universidade Federal do Paraná (UFPR), o segundo (1999) em Guarapuava (PR) pela Universidade Estadual do Centro- Oeste (UNICENTRO), o terceiro (2000) em Ponta Grossa (PR) pela Universidade Estadual de Ponta Grossa e o IV previsto para setembro de 2001, na cidade de Pato Branco, PR, pela Secretaria Estadual do Meio Ambiente (SEMA/PR). Citamos também como antecedente histórico o $1^{\circ}$. Encontro Nacional de Educação Ambiental, ocorrido em Curitiba (PR), no período de 29 de julho a três de agosto de 1991.

Em Santa Catarina as Universidades também tem atuado como parceiras em diversos eventos acadêmicos de Educação Ambiental, dos quais registramos a Conferência Catarinense de E.A. (Florianópolis, 1997), promovida pela Secretaria de Estado do Desenvolvimento Urbano e Meio Ambiente (SDM/ SC) e IBAMA/SC. Santa Catarina enviou suas recomendações para a Conferência Brasileira de E.A. (Brasília-1997) que, por sua vez, elaborou os documentos brasileiros preparatórios para a Conferência Internacional de Tessalonique (Grécia-1997).

Localizadamente podemos citar a Conferência de Educação Ambiental da Bacia Hidrográfica do Itajaí, realizada em Blumenau (SC) no período de 18 e 19 de novembro de 1999, que teve por objetivo reunir as experiências em E.A. do Vale do Rio Itajaí. Este evento promovido pela Fundação de Meio Ambiente de Blumenau (FAEMA) contou com cerca de 200 participantes e resultou na elaboração da Carta de Blumenau e na criação da Rede de Educação Ambiental da Bacia do Rio Itajaí (REABRI), da qual fazem parte as Universidades do Vale do Itajaí (UNIVALI), Universidade Regional de Blumenau (FURB), Universidade para o Desenvolvimento do Alto Vale do Itajaí (UNIDAVI) e Universidade de Joinvile (UNIVILE), além de inúmeras Organizações Não Governamentais. A Universidade Federal de Santa Catarina implantou também um Laboratório de Educação Ambiental, exemplo seguido em 1998 pelo CTTMar da UNIVALI em Itajaí, e mais recentemente pelo Laboratório de Percepção e Educação Ambiental do Instituto de Pesquisas Ambientais -IPA da FURB, em Blumenau. Várias outras universidades catarinenses vêm desenvolvendo ações nesta área, notadamente na implantação de linhas de pesquisa dentro dos Programas de Pós-Graduação, e em Grupos de Pesquisa associados ao CNPq. Este é o exemplo do Mestrado em Educação bem como do Grupo de Pesquisa em Educação, Estudos Ambientais e Sociedade da UNIVALI.

Aqui se observa a grande dificuldade em levantar informações deste processo, uma vez não se dispõe de um banco de dados especifico para estas ações.

No Rio Grande do Sul, o Núcleo de Educação e Monitoramento Ambiental (NEMA), situado na praia do Cassino (Rio Grande, RS), figura como pioneiro nas ações de Educação Ambiental no litoral gaúcho. Outro pioneirismo se deve a Fundação Universidade do Rio Grande (FURG - Rio Grande, RS) pela implantação do primeiro curso de mestrado em E.A. do país. O Mestrado de E.A. da FURG realizou o I Congresso de Educação Ambiental na Área do Mar de Dentro, ocorrido em Rio Grande, no período de 17 a 20 de maio de 2001. Noutra escala, o projeto 'Utopias Concretizáveis: aportes interdisciplinares em Arte, Ciência e Tecnologia para Educação Ambiental; configura-se como importante referência teórica de interdisciplinaridade para a E.A., envolvendo aportes de várias áreas do conhecimento e inúmeras instituições. Este projeto desenvolvido de forma integrada entre instituições do Brasil e Alemanha, utiliza a metodologia proposta pelo professor Wilhelm Walgenbach (IPN - Kiel, Alemanha, Walgenbach 1996a, 1996b), visando um intercâmbio de conhecimentos e idéias com um enfoque holístico e interdisciplinar. $\mathrm{O}$ método adotado tem como núcleo centralizador, uma Exposição - Laboratório de Integração ArteCiência-Tecnologia, que congrega pesquisadores de diversas áreas do conhecimento, em torno de um tema comum: O Fenômeno Água. Atualmente o projeto é coordenado pela pro- 
fessora Cleusa Helena Guaita Peralta (DLA/ FURG).

A realização do I Simpósio Gaúcho de E.A. foi uma iniciativa da Universidade Regional Integrada do Alto Uruguai e das Missões (URI - Campus de Erechim), juntamente com a XII Semana Alto Uruguai do Meio Ambiente, no período de 14 a 18 de agosto de 2000 , funcionou como um importante diagnóstico e catalisador de experiências nos diversos campos de ação da EA.

Com estes exemplos podemos considerar que as universidades começam a assumir a sua responsabilidade no processo de disseminação da E.A. na sociedade e em suas próprias estruturas de ensino, pesquisa e extensão. Estas são apenas algumas referências que tomamos a liberdade de registrar como indício do que vem ocorrendo nas Universidades da região sul. É claro que existem inúmeras outras iniciativas que merecem registro, a exemplo dos cursos de pós-graduação, de vários campos de saber, que têm contemplado em suas linhas de pesquisa a área de EA. Mesmo assim, é nítida a carência de cursos de pós-graduação específicos que tratem das várias dimensões e da complexidade que assumiu a E.A., visto que ela é essencialmente Inter e Transdisciplinar.

Para Nicolescu (1997), "A Universidade é o lugar privilegiado para uma educação dirigida às exigências de nossos tempos. Poderá também ser o eixo central de uma educação direcionada não apenas a crianças e adolescentes, mas também a adultos".

\section{EDUCAÇÃO AMBIENTAL EM ÁREAS COSTEIRAS: A EXPERIÊNCIA DO CENTRO DE ENSINO SUPERIOR DE CIÊNCIAS TECNOLÓGICAS DA TERRA E DO MAR - CTTMAR}

As regiões litorâneas além de abrigarem a maior parte da população mundial, apresentam características ambientais únicas que sempre exerceram fascínio na humanidade. A interface terra, ar e mar, e suas interações pro- duziram ecossistemas únicos, extremamente produtivos, de rara beleza paisagística. De certa maneira, foram eleitos como locais preferenciais de lazer e recreação de diversas camadas sociais, dos grandes centros urbanos do país, e do mundo. Deste modo, representam ainda um elo de ligação dessas pessoas com os elementos naturais, sendo assim uma possibilidade se abre para ações em conservação e Educação Ambiental na zona costeira, o que de fato vem acontecendo no Brasil.

Dentro desta realidade, ressalta-se o papel das Universidades com perfis voltados para a zona costeira, onde se destacam os cursos cuja formação é de natureza interdisciplinar, a exemplo dos cursos de oceanografia da Fundação Universidade do Rio Grande (FURG), da Universidade Estadual do Rio de Janeiro (UERJ) e da Universidade do Vale do Itajaí (UNIVALI). Ao longo do litoral brasileiro, várias iniciativas estimuladas a partir destes cursos contribuíram no processo de Educação e Formação Ambiental Marinha, no resgate da 'Mentalidade Marítima' das populações costeiras e na conservação de ecossistemas costeiros e ambientes insulares.

De 1994 a 1997, a então Faculdade de Ciências do Mar, hoje Centro de Ensino Superior de Ciências Tecnológicas da Terra e do Mar (CTTMar) da Universidade do Vale do Itajaí (UNIVALI), desenvolveu em parceria com o IBAMA, a PETROBRAS e a Polícia Ambiental, - Programa de Orientação e Educação Ambiental para a Reserva Biológica Marinha do Arvoredo. Este Programa foi estruturado a partir da vertente sócio-ambiental da E.A., teve como ponto de partida a relação Homem-Natureza-Sociedade e levou em consideração a problemática envolvendo a realidade natural e social das áreas de entorno e de influência da Reserva (RBMA), com seus inúmeros conflitos e particularidades. Para desencadear o processo de "tomada de consciência"das comunidades litorâneas das áreas de influência e de entorno da Reserva, foram desenvolvidas estratégias específicas para os diferentes públicos alvo dos municípios de 
Itapema, Bombinhas, Porto Belo, Tijucas, Governador Celso Ramos e Florianópolis. Foram produzidos dois documentários em vídeo (versões adulto e infantil), exposições, cursos de capacitação, palestras e oficinas de E.A., materiais impressos voltados para alunos, professores, pescadores (artesanais e industriais), turistas e mergulhadores, bem como três edições do Jornalzinho Ambiental para o público infantil (tiragem: 10.000 exemplares) e professores (1.000 exemplares) direcionados ás 4 as. séries de 51 escolas da rede pública de ensino dos seis municípios das áreas de entorno e de influência RBMA. Como interlocutores do Programa, criou-se "Dico e sua Turma" como personagens de histórias em quadrinhos incorporando aspectos típicos de uma comunidade pesqueira do litoral de Santa Catarina. "Dico e sua Turma" figuram como condutores de histórias representativas da realidade local, além de inúmeros jogos, brincadeiras e atividades educativas.

Vale ressaltar que muitas das comunidades do litoral catarinense possuem identidades próprias com hábitos e costumes muitas vezes de origem secular, que gestaram a sua cultura em pequenas vilas localizadas nas enseadas de Santa Catarina, outrora localidades isoladas, ainda guardam fortes traços de sua herança cultural açoriana. Embora tenham origens similares, muitas vezes surgem especificidades culturais para cada localidade. É neste nível, de escala micro-local, que são construídas as representações sociais de meio ambiente, sujeitas a inúmeras interferências de fenômenos e processos culturais, políticos e religiosos. Assim, os grupos sociais de uma determinada comunidade se estruturam de acordo com uma rede de inter-relações comportamental específica e peculiar, cuja compreensão é fundamental para a estruturação de projetos de E.A. Nas áreas costeiras e nas comunidades litorâneas, isto se evidencia de forma marcante, fazendo com que a Educação Ambiental Comunitária e em Unidades de Conservação tenham um papel importante a desempenhar.
A UNIVALI, através do CTTMar, tem como foco de ações o litoral centro-norte catarinense, o qual possui grande demanda de planejamento e gestão ambiental, devido a velocidade e a desorganização do crescimento urbano, que é fruto de um intenso processo de metropolização acelerada do eixo Curitiba-Florianópolis. Neste sentido o CTTMar implanta, a partir de 1997, - Laboratório de Educação Ambiental em Áreas Costeiras - LEA, visando atender a crescente demanda da região, bem como iniciar o processo de inserção da E.A. nos seus cursos de graduação.

Para cumprir com essa missão, o LEA/ CTTMar se propõe a desenvolver a Educação Ambiental Comunitária e em Unidades de Conservação, através das seguintes sub-linhas de pesquisa: 1) - Desenvolvimento de metodologias e experimentos educacionais interdisciplinares; 2 - Produção de Recursos Pedagógicos; 3 - Capacitação de Multiplicadores e Formação Continuada de Professores; 4 - Educação Ambiental para a Gestão Comunitária (ênfase em Tecnologias Apropriadas e Resíduos Sólidos). Estas pesquisas estão sendo viabilizadas com projetos integrados específicos.

\section{AÇÕES DE EDUCAÇÃO AMBIENTAL DO LEA/CTTMAR NO LITORAL CENTRO- NORTE CATARINENSE}

\section{Educação Ambiental para a Gestão Comuni- tária}

Dentro do Programa Estratégico de Desenvolvimento Sustentável para Regiões Litorâneas (RHAE/MCT/CNPq - UNIVALI/ UNISUL - 1997/99), foi desenvolvida uma atuação no município de Bombinhas e áreas de entorno, através do Projeto de E.A e Participação Comunitária e do sub-projeto "O Resgate de Tecnologias Tradicionais e o Aporte de Tecnologias Apropriadas para o Desenvolvimento Sustentável"' $(\mathrm{MCT} / \mathrm{CNPq} / \mathrm{RHAE}$ - UNIVALI - 1998/99). Estes projetos, de caráter integrador, possibilitaram um diálogo dos 
pesquisadores com as comunidades e grupos sociais do município. Reconhecendo a necessidade de se considerar a identidade cultural, nos projetos e programas de desenvolvimento sustentável, pretendeu-se resgatar tecnologias tradicionais por meio do "saber" e do "fazer" popular. O primeiro grupo social identificado foi o de produtores artesanais de sabão a partir de uma árvore conhecida na região como "Nogueira da Índia" ou "Anoga" (Aleurites moluccana - Euphorbiaceae). Foi estudado um bairro do município e ao todo foram identificadas 12 famílias que ainda mantém esta tradição, sendo que foram registradas através de fotos todas as etapas desta produção. A produção de sabão no passado era realizada por uma grande parte da população feminina. Atualmente apenas uma pequena parcela desta ainda mantém este hábito, restrito às mulheres mais idosas. Isto causa uma preocupação, pois se a transferência cultural não continuar ocorrendo há a tendência do desaparecimento desta atividade. Devido ao grande potencial de produção de sementes, elevado valor terapêutico do óleo (cientificamente comprovado), e a grande carência de empregos permanentes na região, pretende-se desenvolver um projeto piloto de sistema comunitário de produção artesanal de derivados do óleo de elevado valor agregado, como sabonetes e xampus. Esta iniciativa possibilitará a conquista de uma fonte de renda alternativa, garantindo a transferência e manutenção deste "saber fazer" tradicional, inclusive como fortalecimento da autonomia e identidade local. Os resultados deste trabalho levam a crer que a manufatura artesanal de sabão com a Anoga representa uma forma de resistência cultural de parte da comunidade local, fortalecendo sua identidade e história (Fiedler et al. 1998a e 1998b).

O Projeto de E.A. e Participação Comunitária foi fundamental para a capacitação e formação de multiplicadores, voluntários e educadores ambientais, propiciando o resgate da cidadania, a mobilização social e a participação comunitária a partir dos valores culturais, éticos, estéticos e humanistas, conforme preconizado pelos princípios e objetivos da EA.

Capacitação de Multiplicadores e Formação Continuada de Professores

Com os cursos de capacitação de multiplicadores de "Educação Ambiental em Áreas Costeiras", "Ações Comunitárias em Cidadania e Meio Ambiente", "Gerenciamento e Reciclagem de Resíduos Sólidos", "Agentes Juvenis de Turismo e Meio Ambiente", "Monitoramento Ambiental Voluntário nas Escolas", "A Evolução do Grafismo Infantil: aportes interdisciplinares em Educação Ambiental", "Oficinas de Papel Artesanal", "Oficinas de Brinquedos de Sucata" e "Elaboração e Implantação de Trilhas Ecológicas", ampliouse a área de atuação do LEA para todo o litoral centro norte catarinense, realizado em três anos mais de 25 cursos, a maioria realizada em parceria com a Coordenadoria de Extensão (ProPPEx/UNIVALI) e o Sistema Nacional de Emprego (SINE/SC), com recursos do Fundo de Amparo ao Trabalhador (FAT).

Os cursos possuem carga horária variável entre de 40 a 90 horas, podendo haver minicursos de 8 e 12 horas. Desde 1997, já foram realizados cursos nos municípios de Porto Belo (1997), Barra Velha (1998), Bombinhas (1998), Florianópolis (1998), Governador Celso Ramos (1998), Penha (1999), Itajaí (1999/2000), Camboriú (2000), Navegantes (2000) e Balneário Camboriú (2000), Itajaí (2001) atendo uma clientela diversificada em torno de 800 pessoas, visando a atualização profissional, autonomia, geração de renda e inserção do primeiro emprego. Os cursos deram oportunidade a mais de 30 profissionais, entre professores, pesquisadores, acadêmicos dos cursos de oceanografia, Biotecnologia, Geografia, Ciências da Computação, Artes e Comunicação, Psicologia e Engenharia Ambiental da UNIVALI e integrantes de ONG's ambientalistas, para atuarem diretamente com as comunidades destes 
municípios, comunicando os resultados de suas pesquisas e ações.

Desenvolvimento de Metodologias e Experimentos Educacionais Interdisciplinares

\section{“Trilha da Vida: (Re)Descobrindo a Nature- za com os Sentidos"}

O projeto “Trilha da Vida”, em execução desde 1997, foi desenvolvido em parceria com o projeto "Utopias Concretizáveis Interculturais" 3, o Movimento Verde Mar VidaMVMV (Florianópolis, SC), e com apoio da Fundação O Boticário de Proteção à Natureza (FBPN, 1999). Caracteriza-se como um "Experimento Educacional Transdisciplinar" ", no qual as pessoas vivenciam diferentes situações de olhos vendados, exercendo intensamente o tato, olfato, paladar e audição.

Segundo Kobayashi (1991), o elemento mais importante para a Educação Ambiental é permitir às crianças "tocar" a real existência da natureza, pois as crianças raramente esquecem uma experiência direta. São chamados "experimentos de primeira mão" 5 aqueles que propiciam vivências significativas a partir dos sentidos básicos da percepção humana (visão, tato, paladar, olfato, audição e reflexão). Numa sociedade que super valoriza a visão e é dominada pelas imagens, deixamos em segundo plano os outros sentidos. Por outro lado, Joseph Cornell (1996, pg. 18), revela que "as atividades que desconsideram o uso da visão, desviam as preocupações que sentimos em relação a nós mesmos e liberam nossa percepção para captar melhor o mundo a nossa volta".

\section{Mediante "experimentos de primeira} mão", busca-se sensibilizar as pessoas, despertando uma consciência crítica das inter-relações históricas entre a sociedade e a natureza enquanto atividade de Educação Ambiental em nível Inter e Transdisciplinar. Pretende-se também promover a integração homem e natureza, por meio de uma experiência concreta, num ambiente de Floresta Atlântica e ecossistemas costeiros associados enquanto atividade de Educação Ambiental (E.A.) Comunitária e em Unidades de Conservação. Especificamente, busca-se integrar atividades educativas, terapêuticas e conservacionistas, bem como desenvolver metodologias em Percepção e Educação Ambiental, a partir de TriIhas Interpretativas e "Perceptivas" concebidas como "Experimentos Educacionais Transdisciplinares". Tal proposta se contextualiza na vertente sócio-ambiental da E.A.

Em geral, a metodologia fundamenta-se no fato das pessoas deixarem de utilizar momentaneamente o sentido da visão, despertando para os outros sentidos na exploração de "triIhas perceptivas" ". No início da Trilha 0 monitor distribui as vendas e fornece as orientações prévias de acordo com o público alvo. Os participantes são vendados e utilizando-se do tato, olfato e audição, guiam-se através de um cabo-guia, explorando os elementos dispostos ao longo da trilha. Nela, pode-se tocar as essências da Terra, do Ar, da Água e do Fogo com seus sons, gostos, aromas e sensações, bem como perceber as transformações ocorridas entre o homem e a natureza ao longo do tempo. A "Trilha da Vida" pode ser visitada pelo público em geral sendo que as pessoas com visão normal utilizam uma venda nos olhos. Esta atividade pode ser realizada também de forma diretiva com fins terapêuticos (p.ex. nas áreas de psicologia, fonoaudiologia, fisioterapia, pedagogia, saúde e educação especial).

As vivências são desenvolvidas de duas formas até o momento:

1) A primeira ocorre em 03 trilhas integradas e estruturadas em ambiente natural de Floresta Atlântica no Parque Natural das Pedras Vivas (Distrito do Ribeirão da llha - Florianópolis, SC). O sul da llha de Santa Catarina, especialmente o Distrito de Ribeirão da Ilha, ainda possui características marcantes, representadas por um rico patrimônio histórico, cultural e natural, 
aliado à forte mobilização e organização comunitária, representada pelo Movimento Verde Mar Vida (ONG). O Parque possui uma área de 7 ha, que por funcionar nos moldes de uma Reserva Particular de Patrimônio Natural (RPPN), oferece as condições ideais para testar a metodologia e disseminar a Educação Ambiental junto às crianças, a comunidade $e$ todo o público interessado. Cada vivência dura em média duas horas podendo participar até 20 pessoas, sempre com visitas previamente agendadas. Todas as atividades são monitoradas por uma equipe de 6 a 8 educadores ambientais, e visam atender além do sistema educacional, grupos de turistas, da terceira idade, de jovens, empresários e moradores locais.

2) A segunda consiste na simulação de um ambiente natural de Floresta Atlântica associada aos ecossistemas costeiros dentro de escolas, parques ou eventos. A trilha é montada dentro de salas de aula ou ao ar livre (dependendo das condições climáticas e infra-estrutura local), colocando-se sobre mesas e cadeiras, vasos com diferentes tipos de plantas, sons da Floresta Atlântica ${ }^{7}$, serapilheira, areia da praia, água, ventilador, aquecedor, incensos e aromas naturais. Em ambas as situações há a inclusão de uma série de elementos que simbolizam a ação do homem na natureza, bem como objetos e utensílios manufaturados representativos das diferentes fases da humanidade, a exemplo das antropoeras propostas por Dansereau (1967, apud Vieira \& Ribeiro, 1999), configurando-se numa "linha do tempo" ${ }^{8}$. Ao final da "Trilha" o participante retira a venda, sendo então solicitado que realize, individualmente, um desenho do trajeto percorrido, evidenciando os pontos mais significativos. Este desenho é o registro do processo por "Mapa Cognitivo" do percurso da "Trilha da Vida". A partir dos relatos das vivencias individuais $e$ apresentação dos "Mapas Cognitivos", propicia-se uma reflexão em grupo, compartilhando-se as descobertas e experiências vividas. Todo o processo é registrado em vídeo e pos- teriormente transcrito para análise das informações e avaliação do projeto.

O projeto já atendeu mais de 10.000 pessoas em várias localidades, desde a idade préescolar até a $3^{\mathrm{a}}$. idade, em apenas três anos de execução (1998/2001). Para a Trilha fixa, no ano de 2000, a média foi de 2,6 vivencias por mês atendendo uma média de 22 pessoas. O tempo médio para cada vivencia foi de 33 minutos. O maior tempo de vivencia foi de 2 horas e 14 minutos e o menor tempo foi de 10 minutos. Em 2001, a média passou para 1 vivencia por mês, com média de 24 participantes num tempo médio de 40 minutos, sendo o maior tempo 1 hora e 25 minutos e o menor tempo de 12 minutos. Cada vivencia durou em torno de três horas e trinta minutos, englobando a palestra inicial, a vivencia da Trilha, a confecção do mapa mental e o relato em grupo.

Um dos aspectos mais relevantes é o fato do projeto representar a disseminação de novas metodologias de Educação Ambiental valorizando as diversidades cultural e ambiental, ao nível comunitário em significativas vivências em diferentes níveis de inter-relações. Ou seja, pode-se trabalhar as relações "Eu - Meio Ambiente", "Eu - O Outro" e "Eu - Eu Mesmo". Como resultado imediato, o projeto tem gerado renda e trabalho para senhoras da comunidade que passaram a fornecer alimentação aos participantes das vivencias valorizando os hábitos alimentares típicos da região, bem como aos moradores locais e membros do Movimento Verde Mar Vida (MVMV), que passaram a trabalhar na implantação das trilhas e execução das atividades. O projeto representa uma alternativa de sustentabilidade para o Movimento, garantindo a continuidade das ações de conservação do local.

Ressalta-se que esta proposta tem o caráter nitidamente inter e transdisciplinar, possibilitando a integração de diversas áreas do conhecimento dentro de um objetivo comum, que é reaproximar as pessoas da natureza, em especial da biodiversidade da Floresta Atlântica. A vivência propicia ao Homem, uma leitura sensível, mais consciente e menos "destrutiva" 
da natureza, por meio de experiências diretas. No que se refere ao objetivo proposto de religar as pessoas com a natureza, os relatos tanto pelo mapa mental como pelos vídeos demonstram que a supressão do sentido da visão realmente potencializa os demais sentidos, e que a vivencia é única e marcante, ficando uma profunda reflexão das pessoas sobre as inter-relações ente sociedade e natureza no tempo e no espaço, reforçando a visão sócio-ambiental da E.A. Como continuidade estão sendo criados núcleos disseminadores da metodologia nos estados de Santa Catarina, Paraná, Rio Grande do Sul, São Paulo e Bahia.

\section{Programa "Olho Vivo" de Monitoramento Ambiental Voluntário}

O programa "Olho Vivo" de Monitoramento Ambiental Voluntário (MAV) vem sendo desenvolvido pela UNIVALI desde 1997. O Programa consiste de um Monitoramento Ambiental Voluntário, sistemático e continuo de parâmetros da água costeira, no município de Penha (SC). O trabalho envolve jovens da própria comunidade tradicional local (pescadores/maricultores) os quais coletam dados diariamente de maneira responsável (Bonilha et al. 1999a e 1999b), estendendo a participação da comunidade local ao processo de gestão do espaço costeiro. Atualmente uma família de pescadores vem desenvolvendo o trabalho, o qual já acumulou cerca de 10.000 dados. Os resultados do projeto estão atendendo cerca de 30 projetos de pesquisa do CTTMar/ UNIVALI, como parte da demanda de informações necessárias à gestão do parque aqüícola de moluscos marinhos, localizado na enseada da Armação do Itapocoroy (Penha-SC).

Reconhecendo o grande potencial do MAV para atividades de Educação Ambiental, a partir de abril de 1999 foi incorporada ao programa "Olho Vivo" uma atividade educativa dentro de uma escola da rede pública do município de Penha (Araujo et al. 1999), dando início ao monitoramento ambiental voluntário nas escolas.
"Clube Olho Vivo" de Monitoramento Ambiental Voluntário nas Escolas"

Clube Olho Vivo é um projeto piloto de Monitoramento Ambiental Voluntário nas escolas desenvolvido na Escola Básica Municipal Ariribá, no Bairro da Praia Brava - Itajaí (SC). O projeto é executado em parceria com a ONG Ambientalista "Voluntários pela Verdade Ambiental", com a Prefeitura Municipal de Itajaí, recebendo patrocínio da PETROBRAS (Mentges et al., 2000).

O projeto visa a construção da cidadania ambientalista através da fundação de um clube de crianças voluntárias. O projeto é adotado pela escola como currículo, onde participam professores voluntários capacitados coordenando as atividades, as quais são programadas em reuniões pedagógicas.

As crianças se inscrevem como voluntárias ao projeto, e montam um clube aos moldes de uma ONG Ambientalista, com estatuto próprio elaborado pelas próprias crianças. $\mathrm{O}$ objetivo maior do clube é o monitoramento meteorológico local, registro de organização de dados e informações ambientais, mapeamento e reconhecimento dos ecossistemas do bairro, reconhecimento dos ciclos naturais, e desenvolvimento de posturas pró-ativas com relação ao meio ambiente e sociedade no espaço micro-local, baseado na perspectiva da pirâmide informacional proposta por Jeguier et al. (1987, apud Machado, 1995). Os dados gerados pelas crianças do clube são disponibilizados para serem inseridos de maneira transversal no currículo escolar, bem como na construção de calendários ecossistêmicos (D'Olne Campos, 1994).

O projeto está fundamentado no construtivismo, na educação pela pesquisa (Demo, 1996), e na pedagogia da autonomia (Freire, 1996), partindo do fortalecimento do indivíduo em direção ao fortalecimento da comunidade, visando ações regenerativas autônomas no meio ambiente do bairro.

Atualmente cerca de 60 crianças já passaram pelo Clube Olho Vivo, tendo produzido 
resultados bastante significativos com relação a dimensão cognitiva e afetiva do processo educativo.

\section{CONSIDERAÇÕES}

Estes projetos são exemplos de novas metodologias em E.A. Comunitária e em Unidades de Conservação, bem como no Ensino Formal, a partir do envolvimento direto da comunidade através da parceria com Organizações Não Governamentais, dentro do princípio de Voluntariado, da solidariedade, e dos fundamentos do ecodesenvolvimento (sensu Sachs, 1986).

Outro aspecto de relevância para a Educação Ambiental Comunitária em áreas costeiras é sua interface com os processos de gestão comunitária patrimonial (Vieira \& Weber, 1997) e com as propostas do programa de gerenciamento costeiro tanto nacional como estadual. $O$ atual programa de gerenciamento costeiro para o Estado de Santa Catarina, não contempla de forma estrutural os pressupostos educativos em sua concepção, tampouco a dimensão comunitária dentro do processo de gestão. Isto, aliado ao fato do gerenciamento costeiro se dar em escala regional, não fortalecendo as ações e tomadas de decisão na escala micro-local, ou seja, no âmbito comunitário do bairro, que é, via de regra, onde se forjam as representações sociais, e onde se desenvolvem os processos degradativos ou regenerativos do meio ambiente. Aqui mais uma vez, percebe-se o quanto a Educação Ambiental Comunitária, pode contribuir para uma gestão compromissada com a manutenção da qualidade ambiental do litoral brasileiro e com as necessárias transformações sociais a partir de mecanismos realmente participativos.

Chegou a hora de se empreender uma somatória de esforços que sensibilizem as pessoas, em especial as que detêm o poder de decisão, para a urgência de se conservar e estabelecer mecanismos mais legítimos de participação popular no processo de gestão ambiental e conservação do litoral brasileiro.

A Educação Ambiental certamente será indutora deste processo, cabendo aos educadores ambientais uma árdua tarefa. Pois podese considerar a Educação Ambiental como o ponto onde se cruzam os caminhos que, mediante Educação, Ciência e Cultura, tendem a conciliar desenvolvimento e meio ambiente e a fortalecer a aliança fundamental do Homem com a Natureza.

\section{AGRADECIMENTOS}

A todos os membros de nossa equipe (comunidade) interdisciplinar que participam dos projetos do LEA: Cleuza Helena Guaita Peralta (Transdisciplinaridade e Arte EducaçãoDepto. Letras e Arte -FURG), Fernanda de Salles Cavedon (Cidadania - Lab. de Direito Ambiental - UNIVALI), Homero Haymussi (Meteorologia-UNIVALI), Nara Regina Crizel Marone (Experimentos Interdisciplinares - ArteEducação-FURG), Rafael Medeiros Sperb (Gerenciamento Costeiro- UNIVALI), Rodrigo Medeiros (Pesca Artesanal-UNIVALI), Cristiane Manique Barreto (História-UNIVALI), Rosimeri Carvalho Marenzi (Eng. Florestal e Percepção Ambiental - UNIVALI); Sergey Alex de Araujo (Geoprocessamento-UNIVALI), Sérgio de Freitas Borges (Hidrogeologia-UNIVALI), Stella Maris Brum Lopes (Fonoaldiologia-UNIVALI), Yára Christina Cezário Pereira (PedagogiaUNIVALI), Wilhelm Walgenbach (Experimentos Educacionais Transdisciplinares na Educação - IPN/ Universidade de Kiel - Alemanha), Carlos de Oliveira (SMMA - Curitiba, PR) e Rita de Cássia Santarém (Arte Educadora - Curitiba, PR) Ângela Ferreira Schmidt (Mestrado em Educação-PUC/SP); e estagiários: Fabrício Menezes Ramos, Tatiane Mentges, Inaê Adorno de Araújo, Fernando Fiedler, Renata Costella Acauan, Irene Marschalek, Fernanda Terra Stori. 


\section{BIBLIOGRAFIA}

Ab'saber, A. N. 1991 (Re) Conceituando Educação Ambiental. MAST/CNPq.

Araujo, I.A.; Bonilha, L.E.C.; Matarezi, J.; Marenzi, A.W.C. \& G.C. Manzoni. 1999. O Monitoramento Ambiental Voluntário como Atividade Educativa nas Escolas. pg 147-154. In: Anais do II Encontro Paranaense de Educação Ambiental IIEPEA, UNICENTRO, Guarapuava-PR, 57 de nov. 1999.

Bertolini, B. 1996. Paisagens Sonoras do Planeta: Floresta Atlântica. CD produzido pela Naturenet, Fundação Cultural de Curitiba e Fundação o Boticário de Proteção à Natureza. Curitiba, PR.

Bissio, B. 1991. Estamos Todos no Mesmo Planeta. Revista Ecologia e Desenvolvimento. Novo Mundo, ano 1, no. 1.

Bonilha, L.E.C.; Polette, M.; Matarezi, J. \& I. Araujo 1999a. Implantação de um Programa de Monitoramento Ambiental Voluntário na Zona Costeira: Aspectos Metodológicos e Estudo de Caso - Programa Olho Vivo. Revista de Estudos Ambientais, Blumenau, 1(2): 59-70.

Bonilha, L.E.C.; Matarezi,J; Polette, M.; Ribeiro, M.R.; Haymussi, H.; Lamas, H.D.; Araujo, I.; Bacilla, C. \& A.P. Grando. 1999b. Integrando Pesquisa e Educação nas Atividades de Extensão: Programa de Monitoramento Ambiental Voluntário do Litoral Centro Norte Catarinense: Programa "Olho Vivo". Rev.Tecnol.Ambiente, Criciúma, 5(2): 85-100.

BRASIL. 1991. Presidência da República. O Desafio do Desenvolvimento Sustentável. Relatório do Brasil para a Conferência das Nações Unidas sobre Meio Ambiente e Desenvolvimento - CNUMAD. Brasília-DF.

Cornell, J. 1996. Brincar e Aprender com a Natureza: Guia de Atividades Infantis para Pais e Monitores. Tradução: Maria Emilia de Oliveira. Editora SENAC - São Paulo, Companhia Melhoramentos.
Czapski, S. 1998. A Implantação da Educação Ambiental no Brasil. Brasília - DF; Coordenação de Educação Ambiental MEC.

Delors, J. 1999. Educação: Um Tesouro a Descobrir. Relatório para a UNESCO da Comissão Internacional sobre Educação para o Século XXI. $2^{a}$ edição, São Paulo: Cortez; Brasília, DF: MEC: UNESCO,

Demo, P. 1996. Pesquisa e Construção de Conhecimento: metodologia científica no caminho de Habermas. Ed. Tempo Brasileiro. Rio de Janeiro, RJ.

D'olne Campos, M. 1994. Fazer o Tempo e o Fazer do Tempo: rítmos em concorrência entre o ser humano e a natureza. Revista Ciência \& Ambiente. $N^{0} \cdot 8$ - Educação Ambiental. UFSM, Santa Maria, RS.

EDAMAZ. 2000. La Educación Ambiental: Uma Relación Constructiva entre la Escuela y la Comunidad. Guia de Formación e Intervención en Educación Ambiental. Ed. EDAMAZ/Université du Québec à Montreal/ Bibliothèque Nationale du Canadá/ Bibliothéque Nationale du Québec.

FBPN 1999. Trilha da Vida: (Re)Descobrindo a Natureza com os Sentidos. Projeto UNIVALI/Movimento Verde Mar Vida. FUNDAÇÃO O BOTICÁRIO DE PROTEÇÃO À NATUREZA.

Fiedler, F; Matarezi, J. \& L. E. C. Bonilha 1998a. O Resgate de Tecnologias Tradicionais e a Utilização de Tecnologias Apropriadas como Suporte para o Desenvolvimento Sustentável e a Educação Ambiental Comunitária no Município de Bombinhas (SC). Pg. 280. In: Livro de Resumos do Seminário Integrado de Iniciação Científica, Blumenau: FURB

Fiedler, F; Bonilha, L. E. C.; Matarezi, J.; Bufrem, A.M. \& F. L. Diehl. 1998b. A Arte de Fazer Sabão no Município de Bombinhas(SC): Tecnologias Tradicionais como Suporte para o Desenvolvimento Sustentável e a Educação Ambiental Comunitária. p. 34-36. In: Anais da XI Semana 
Nacional de Oceanografia: Oceanografia e suas interfaces. Resumos Expandidos Anais. Rio Grande (RS): FURG.

Freire, P. 1996. Pedagogia da Autonomia: Saberes Necessários à Prática Educativa. $15^{\mathrm{a}}$ Edição. Editora Paz e Terra, São Paulo, $165 \mathrm{p}$.

Kobayashi, T. 1991. A Suggestion about Environment Education Using the Five Senses. Marine Pollution Bulletin, 23: 623626.

LEI № 9.795. Política Nacional de Educação Ambiental. Brasília (DF): Diário Oficial / Imprensa Oficial. 28 de abril de 1999.

Machado, N.J. 1995. Epistemologia e Didática: as concepções de conhecimento e inteligência e a prática docente. Ed. Cortez

Marone, N. R. C. 2000. Espelho: Um Recorte na Grande Complexidade - Estudo de uma Alternativa Transdisciplinar como Possibilidade para a Formação de Professores. Dissertação de Mestrado, Universidade Federal de Pelotas - FaE.

MEC, 1997. Programa Nacional de Educação Ambiental. - PRONEA. Coordenadoria de Educação Ambiental. Acordo Brasil/ UNESCO. Brasília.

Medina, N. M \& E.C. Santos. 2000. Educação Ambiental: Uma Metodologia Participativa de Formação. Petrópolis (RJ): Ed. Vozes.

Medina, N. M. 1994. Amazônia - Uma Proposta Interdisciplinar de Educação Ambiental. Documentos Metodológicos. MMA/IBAMA. Brasília.

Mentges, T.; Ramos, F.M.; Matarezi, J. \& L.E.C. Bonilha. 2000. Programa de Monitoramento Ambiental Voluntário nas Escolas: Uma Experiência Piloto em Educação Ambiental - Clube Olho Vivo. Pg. 339-340. In: Anais da XIII Semana Nacional de Oceanografia. 29 de outubro a 3 de Novembro de 2000. Universidade do Vale do Itajaí -UNIVALI.

Nicolescu, B. 1997. Evolução Transdisciplinar da Universidade: Condição para o Desenvolvimento Sustentável. Universidade "Pierre et Marie Curie", Paris, França Aliança por um Mundo Responsável e Unido. Novem- bro de 1997. http: //www. cetrans.futuro.usp.br/cartadatransport.html Nicolescu, B. 1999. O Manifesto da Transdisicplinaridade. TRIOM, São Paulo. Pedrini, A. G. 1997. Educação Ambiental: Reflexões Práticas e Contemporâneas. Ed. Vozes. 2 ${ }^{\text {a }}$. Ed. Petrópolis - RJ.

Peralta, C. H. G. 1997. O Conceito Utopias Concretizáveis - Elemento Gerador de um Programa de Educação Ambiental Centrado na Interdisciplinaridade. Dissertação de Mestrado. Fundação Universidade do Rio Grande- FURG, Mestrado em Educação Ambiental .

Peralta, C.H.G. 2001. Experimentos Educacionais: Eventos Heurísticos Transdisciplinares. Anais do I Congresso de Educação Ambiental na Área do PróMar-de-Dentro. Rio Grande-FURG, 17-20 de maio de 2001. No Prelo.

Rebouças, A. C. 1989. Estudos de Impactos Ambientais, Numa Nova Perspectiva de Multiprofisional. In: Anais do XIII Simpósio Anual da ACIESP, Meio Ambiente: Sua ocupação e recuperação.

Reigota, M. 1994. O Que é Educação Ambiental. Editora Brasiliense, São Paulo.

Reigota, M. 1995. Meio Ambiente e Representação Social. Editora Cortez, São Paulo.

Reigota, M. 1999. A Escola e a Floresta: Por uma Educação Pós-Moderna. Editora Cortez, São Paulo.

Sachs, I. 1986. Ecodesenvolvimento: Crescer sem Destruir. Editora Vértice, São Paulo, $205 \mathrm{p}$.

Sato, M. \& J.E. Santos. 2001. Tendências nas Pesquisas em Educação Ambiental. In: M. REIGOTA; F. NOAL \& V. BARCELOS (Eds.). Caminhos da Educação Ambiental: UDUNISC, Santa Cruz do Sul. No Prelo.

UNESCO 1980. Environmental Education in the Ligth of Tbilisi Conference. UNESCO Publication.

Vasconcellos, J. M. de O. 1996. Bases Gerais da Educação Ambiental e Interpretação da Natureza In: Curso de Manejo de Áreas 
Naturais Protegidas: Teoria e Prática. 19 a 02 de maio de 1996. Curitiba e Guaraqueçaba, UNILIVRE.

Vieira, P.F. \& M. A. Ribeiro (Eds.) 1999. Ecologia Humana, Ética e Educação: A Mensagem de Pierre Dansereau. Porto Alegre: Pallotti; Florianópolis: APED.

Vieira, P.F. \& J. Weber (Eds.) 1997. Gestão de Recursos Naturais Renováveis e Desenvolvimento: Novos Desafios para a Pesquisa Ambiental. $1^{a}$ Edição, Editora Cortez.

Walgenbach, W. 1996a. Conceitos Básicos de Educação Ambiental: do Ponto de Vista da Educação Categorial. Revista Ambiente \& Educação Considerações Básicas sobre um Programa de Educação Ambiental. Vol. 1. Fundação Universidade do Rio Grande, Rio Grande (RS).

Walgenbach, W. 1996b. Laboratório do Pensamento Sistêmico Interdisciplinar (Modelagem Qualitativa de Sistemas Interdisciplinares). Revista Ambiente \& Educação Considerações Básicas sobre um Programa de Educação Ambiental. Vol. 1. Fundação Universidade do Rio Grande, Rio Grande (RS).

\section{COMENTÁRIOS}

${ }^{1}$ Professor/Pesquisador do CTTMar, Universidade do Vale do Itajaí, SC - jmatarezi @cttmar.univali.br, Rua Uruguai, 458 - Caixa Postal 360 - Itajaí, SC. CEP: 88-302-202 Fone (0xx47) 341-7723, Laboratório de Educação Ambiental em Áreas Costeiras.

2 Professor/Pesquisador do CTTMar e do CEJURPS da UNIVALI. bonilha @ cttmar. univali. br, Laboratório de Educação Ambiental em Áreas Costeiras.

${ }^{3} \mathrm{~A}$ existência deste programa, há mais de dez anos em andamento na FURG, já possibilitou a elaboração de uma tese de pós-doutorado, duas dissertações de mestrado (Peralta, 1997 e Marone, 2000) e uma monografia de conclusão do curso de Educação Artística - FURG, de Luciane Germano Goldberg. Informalmente, muitos trabalhos acadêmicos vêm sendo veiculados, a partir desta temática.

${ }^{4}$ Conceito relativo aos aportes teóricos do projeto Utopias Concretizáveis Interculturais coordenado pela Profa. Cleusa H. G. Peralta (FURG/ DLA), bem como da sistematização teórica do Prof. Wilhem Walgenbach do Instituto de Pedagogia das Ciências Naturais - IPN (Universidade de Kiel, Alemanha). Fundamentado no texto: "Experimentos educacionais: eventos heurísticos transdisciplinares" de Cleusa Helena Guaita Peralta (Peralta, no prelo)

${ }^{5}$ São chamados "experimentos de primeira mão" aqueles que propiciam vivências significativas a partir dos sentidos básicos da percepção humana (visão, tato, paladar, olfato, audição e reflexão). De acordo com Jane $M$. de O. Vasconcellos (1996), experimentos de primeira mão: "podem ser considerados como um ciclo de investigação ou um processo de elaboração de perguntas e busca de respostas. A partir de um tema, juntando a observação direta do ambiente, com o conhecimento anterior. Formula-se uma pergunta. A resposta para esta pergunta exige experimentação (ação) e reflexão. Estas, por sua vez, levam a novas perguntas que requerem novas respostas, e assim por diante. $O$ cérebro e todos os sentidos poderão ser utilizados neste processo de busca e descoberta". Comungar com a natureza por meio do tato, do olfato, do paladar e da audição desconsiderando a visão é um dos fundamentos das atividades propostas no projeto "Trilha da Vida".

${ }^{6}$ Termo adotado pelo LEA/CTTMar, para designar as atividade de interpretação ambiental realizadas em trilhas ecológicas utilizando-se os experimentos de primeira mão, excetuando-se, num primeiro momento, a visão.

${ }^{7}$ Para simular a diversidade de sons da Floresta Atlântica,utilizamos o CD Floresta Atlântica da série Paisagens Sonoras do Planeta, de 
autoria de Beto Bertolini (1996), editado pela Naturenet em Curitiba, PR.

${ }^{8} \mathrm{Na}$ Linha do Tempo existem objetos manufaturados, artesanais, industriais e tecnológicos que simbolizam as diferentes fases da huma- nidade bem como a identidade e a cultura local. Foi a forma encontrada para contextualizar a proposta dentro da vertente sócio-ambiental da EA, onde se pretende integrar o homem ao meio e gerar uma reflexão sobre as relações Homem/Natureza no espaço/tempo. 